\title{
Gravimetri Tidak Langsung untuk Menetapkan Jumlah Air Kristal
}

\author{
Direct Gravimetry to Set The Crystal Water Amount \\ Petrus Darmawan ${ }^{1}$ dan Soebiyanto ${ }^{2 *}$ \\ ${ }^{1}$ Fakultas Teknik, Universitas Setia Budi Surakarta \\ ${ }^{2}$ Fakultas Ilmu Kesehatan, Universitas Setia Budi Surakarta \\ *Corresponding author: soebixto@gmail.com
}

\begin{abstract}
ABSTRAK
Gravimetri merupakan salah satu bagian utama dalam Kimia Analisa. Air kristal yang merupakan konstituen dalam beberapa searyawa kimia dapat ditentukan pula dengan cara gravimetri langsung, dimana bahan dilakukan pemanasan dengan oven selama waktu tertentu sampai berat konstan.

Penelitian ini diharapkan dapat dijadikan alternatif yang lain pada penetapan jumlah air kristal dalam suatu senyawa kimia, dimana dalam hal ini dilakukan penambahan reagen pengendap $\mathrm{Na}_{2} \mathrm{SO}_{4} 3 \mathrm{M}_{\text {pada larutan } \mathrm{BaCl}}$. Endapan yang terbentuk kemudian dilakukan pemanasan dengan oven sampai didapat berat konstan.

Hasil penelitian menunjukkan bahwa dengan cara gravimetri tidak langsung, tidak berbeda dengan cara gravimetri langsung.
\end{abstract}

Kata kunci : air kristal, gravimetri

\section{ABSTRACT}

Gravimetry is one of the analyst chemistry. Crystal water which is the constituent in many Compound of chemistry and can be made by gravimetry directly the material is hit by the oven until the weight is constant. That procedure is usually used lately.

This research will help to another alternative which is done by adding reagent chemistry $\mathrm{Na}_{2} \mathrm{SO}_{4} 3 \mathrm{M}$ in the solution $\mathrm{BaCl}_{2}$. The precipitation which is formed, and then is done by hitting in oven until we have got the constant weight.

The result of this research is shown that the procedure of gravimetry is not directly which isn't different way of indirect gravimetry.

Key Words : crystal water, gravimetric

\section{PENDAHULUAN}

Pada dasarnya, air merupakan konstituen dari suatu bahan. Dengan demikian tentunya kadar air dalam suatu bahan dapat ditentukan. Tetapi bahan yang dianalisa sering mengandung air yang jumlahnya tidak menentu. Sebagai contoh adalah tanah, bahan yang berasal dari hewan dan tumbuhan, bahan higroskopis dan sebagainya. Jumlah air yang terkandung sering tergantung dari perlakuan yang telah dialami bahan, kelembaban udara tempat penyimpanannya dan lain sebagainya. Kenyataan seperti itu terkadang memungkinkan kesalahan penentuan kadar air, belum lagi dengan air bahan lain yang mudah menguap dan ikut menguap bersama-sama dengan air sewaktu dipanaskan serta teruainya bahan. Air dapat dikandung oleh bahan dengan bermacam cara, yaitu air yang terkandung/terikat secara fisik dan air yang terikat secara kimia. Untuk yang pertama, untuk menghilangkan air yang terikat fisik diperlukan panas rendah, sekedar untuk menguapkannya. Umumnya suhu 100$105^{\circ} \mathrm{C}$ sudah mencukupi, kadang cukup dengan membiarkan bahan yang bersangkutan terkena udara bebas/angin. Jumlah air yang terikat tidak tertentu. Contoh untuk air yang terikat secara fisik adalah air terlarut, air adsorpsi dan air oklusi. Sedangkan untuk air yang terikat secara kimia jumlahnya tertentu. Sebagai contoh adalah air kristal dan air konstitusi.

Air kristal merupakan bagian dari struktur kristal pada senyawa tertentu dan disebut sebagai hidrat kristal. Jumlah air kristal pada 
tiap senyawa tidak sama, seperti $\mathrm{BaCl}_{2} \cdot 2 \mathrm{H}_{2} \mathrm{O}$, $\mathrm{CuSO}_{4}, 5 \mathrm{H}_{2} \mathrm{O}, \mathrm{Na}_{2} \mathrm{SO}_{4}, 10 \mathrm{H}_{2} \mathrm{O}$, pada contoh $\mathrm{CuSO}_{4} \cdot 5 \mathrm{H}_{2} \mathrm{O}$, pengertiannya adalah bahwa di dalam kristal tembaga sulfat, tiap-tiap molekul diikat pada 5 molekul $\mathrm{H}_{2} \mathrm{O}$. Jika zat itu dipanaskan, keluarlah uap air, warna biru berubah menjadi warna putih dan zat yang tinggal hanya melekul $\mathrm{CuSO}_{4}$ saja. Hal inilah yang menjadi dasar metoda penetapan jumlah air kristal dalam sebagian besar senyawa berair kristal. Metode ini dalam analisa kimia disebut gravimetri, dimana pada dasarnya penetapan jumlah zat didasarkan penimbangan pada berat konstan. Metoda penetapan air kristal dengan pemanasan langsung senyawa berair kristal pada kenyataannya merupakan metode yang sering digunakan dalam pembelajaran selama ini dari penelitian ini diharapkan ada wacana baru dalam pembelajaran, walaupun istilah gravimetri langsung dan gravimetri tidak langsung perbedaannya hanya terletak pada proses dilakukannya pengendapan terlebih dahulu atau tidak. Tetapi setidaknya tahap-tahap dalam gravimetri yang meliputi pengendapan, penyaringan, pencucian endapan, pengeringan endapan dengan atau tanpa pemijaran serta penimbangan dapat dilakukan secara benar.

\section{METODE PENELITIAN}

\section{Alat dan Bahan}

Batang pengaduk, Beaker glass $100 \mathrm{ml}$, Botol timbang, Buret, Corong gelas, Eksikator, Kertas saring Whatman, Neraca analitis, Pipet tetes, Kristal $\mathrm{BaCl}_{2}$ (E. Merck), Larutan $\mathrm{Na}_{2} \mathrm{SO}_{4}$ $3 \mathrm{M}$, Akuades.

\section{Prosedur Penelitian}

A. Penetapan air kristal secara langsung

1. Oven botol timbang pada suhu $125^{\circ} \mathrm{C}$ selama 30 menit.

2. Dinginkan dalam eksikator selama \pm 10 menit.

3. Timbang botol timbang tersebut dan ulangi perlakuan 1 - 2 di atas sampai didapat berat konstan.

4. Masukkan $\pm 1,5$ gram kristal $\mathrm{BaCl}_{2}$ ke dalam botol timbang, kemudian timbang neraca analitis.

5. Oven pada suhu $125^{\circ} \mathrm{C}$ selama 120 menit, kemudian dinginkan dalam eksikator selama \pm 20 menit.

6. Timbang botol timbang tersebut dan ulangi perlakukan No. 5 sampai didapat berat konstan.

\section{B. Penetapan air kristal secara tidak langsung}

1. Timbang $\pm 1,5$ gram kristal $\mathrm{BaCl}_{2}$ dan masukkan ke dalam beaker glass kemudian larutkan dengan aquadest sebanyak $50 \mathrm{ml}$.

2. Tambahkan larutan $\mathrm{Na}_{2} \mathrm{SO}_{4} 3 \mathrm{M}$ tetes demi tetes melalui buret sambil diaduk pelanpelan sampai pengendapan sempurna.

3. Uji apakah pengendapan sudah sempurna dan cuci endapan dengan aquadest 4

4. Saring endapan dengan kertas saring yang sudah diketahui beratnya.

5. Masukkan kertas saring dan endapan ke dalam botol timbang yang sudah diketahui berat konstannya.

6. Oven pada suhu $125^{\circ} \mathrm{C}$ selama 120 menit, kemudian dinginkan dalam eksikator selama \pm 20 menit.

7. Timbang botol timbang yang berisi kertas saring dengan endapan tersebut dan ulangi perlakukan No. 6 sampai didapat berat konstan.

\section{HASIL DAN PEMBAHASAN \\ Hasil Penelitian}

I. Secara Langsung

A. Penimbangan botol timbang (Tabel 1,

2,3)

B. Penimbangan botol timbang + Sampel

(Tabel 4, 5, 6)

II. Secara Tidak Langsung
A. Penimbangan Beaker Glass + Sampel
(Tabel 7) 
Tabel 1 Penimbangan Botol Timbang I (Secara Langsung )

\begin{tabular}{|c|c|c|}
\hline Ke & $\begin{array}{c}\text { Botol timbang I } \\
(\mathrm{mg})\end{array}$ & Keterangan : \\
\hline 1 & 19771,2 & - Sebelum perlakuan : 19771,2 mg \\
2 & 19576,8 & - Sebelum perlakuan $1: 19576,8 \mathrm{mg}$ \\
3 & 19648,4 & - Sebelum perlakuan $2: \mathbf{1 9 6 4 8 , 4} \mathbf{~ m g}$ \\
4 & 19648,4 & - Sebelum perlakuan 3 : 19648,4 mg \\
\hline
\end{tabular}

Tabel 2 Penimbangan Botol Timbang II (Secara Langsung )

\begin{tabular}{|c|c|c|}
\hline Ke & $\begin{array}{c}\text { Botol timbang II } \\
(\mathrm{mg})\end{array}$ & Keterangan : \\
\hline 1 & 21568,2 & - Sebelum perlakuan : $21568,2 \mathrm{mg}$ \\
2 & 21403,6 & - Sebelum perlakuan $1: 21403,6 \mathrm{mg}$ \\
3 & 21345,2 & - Sebelum perlakuan $2: \mathbf{2 1 3 4 5 , 2} \mathbf{~ m g}$ \\
4 & 21345,2 & - Sebelum perlakuan 3 : 21345,2 $\mathbf{~ m g}$ \\
\hline
\end{tabular}

Tabel 3 Penimbangan Botol Timbang III (Secara Langsung )

\begin{tabular}{|c|c|c|}
\hline $\mathrm{Ke}$ & $\begin{array}{l}\text { Botol timbang III } \\
(\mathrm{mg})\end{array}$ & Keterangan : \\
\hline $\begin{array}{l}1 \\
2 \\
3 \\
4\end{array}$ & $\begin{array}{l}21104,6 \\
21004,4 \\
21004,2 \\
21004,2\end{array}$ & $\begin{array}{l}\text { - Sebelum perlakuan }: 21104,6 \mathrm{mg} \\
\text { - } \\
\text { - Sebelum perlakuan } 1: 21004,4 \mathrm{mg} \\
\text { - Sebelum perlakuan } 2: \mathbf{2 1 0 0 4 , 2} \mathbf{~ m g} \\
\text { - Sebelum perlakuan } 3: \mathbf{2 1 0 0 4 , 2} \mathbf{~ m g}\end{array}$ \\
\hline
\end{tabular}

Tabel 4 Penimbangan Botol Timbang I + Sampel I (Secara Langsung )

\begin{tabular}{|c|c|c|}
\hline $\mathrm{Ke}$ & $\begin{array}{c}\text { Botol timbang } \\
+ \\
\text { Sampel I (mg) }\end{array}$ & Keterangan : \\
\hline $\begin{array}{l}1 \\
2 \\
3 \\
4 \\
5\end{array}$ & $\begin{array}{l}21414,5 \\
21330,2 \\
21237,8 \\
21147,2 \\
21147,2\end{array}$ & $\begin{array}{ll}\text { - } & \text { Sebelum perlakuan }: 21414,5 \mathrm{mg} \\
\text { - } & \text { Sebelum perlakuan } 1: 21330,2 \mathrm{mg} \\
\text { - } & \text { Sebelum perlakuan } 2: 21237,8 \mathrm{mg} \\
\text { - } & \text { Sebelum perlakuan } 3: \mathbf{2 1 1 4 7 , 2} \mathbf{~ m g} \\
\text { - } & \text { Sebelum perlakuan } 4: \mathbf{2 1 1 4 7 , 2} \mathbf{~ m g}\end{array}$ \\
\hline
\end{tabular}

Tabel 5 Penimbangan Botol Timbang II + Sampel I I (Secara Langsung )

\begin{tabular}{|c|c|c|}
\hline Ke & $\begin{array}{c}\text { Botol timbang } \\
+ \\
\text { Sampel II (mg) }\end{array}$ & Keterangan : \\
\hline 1 & 22779,4 & - Sebelum perlakuan : $22779,4 \mathbf{~ m g}$ \\
2 & 22605,2 & - Sebelum perlakuan $1: 22605,2 \mathbf{~ m g}$ \\
3 & 22561,6 & - Sebelum perlakuan 2 : 22561,6 mg \\
4 & 22561,6 & - Sebelum perlakuan 3 : 22561,6 mg \\
\hline
\end{tabular}

Tabel 6 Penimbangan Botol Timbang III + Sampel III (Secara Langsung )

\begin{tabular}{|c|c|c|c|}
\hline $\mathrm{Ke}$ & $\begin{array}{c}\text { Botol timbang } \\
+ \\
\text { Sampel III (mg) }\end{array}$ & \multicolumn{2}{|c|}{ Keterangan : } \\
\hline 1 & 22437,8 & - Sebelum perlakuan & : $22437,8 \mathrm{mg}$ \\
\hline 2 & 22310,2 & - Sebelum perlakuan 1 & : $22310,2 \mathrm{mg}$ \\
\hline 3 & 22270,8 & - Sebelum perlakuan 2 & : $22270,8 \mathrm{mg}$ \\
\hline 4 & 22220,8 & - Sebelum perlakuan 3 & : $22220,8 \mathrm{mg}$ \\
\hline 5 & 22220,6 & - Sebelum perlakuan 4 & : 22220,6 mg \\
\hline 6 & 22220,6 & - Sebelum perlakuan 5 & : 22220,6 mg \\
\hline
\end{tabular}

\section{B. Penimbangan Botol Timbang (Tabel 8,} 9, 10)
C. Penimbangan Botol Timbang + Kertas Saring + Endapan (Tabel 11) 
Tabel 7 Penimbangan Beaker Glass + Sampel (Secara Tidak Langsung )

\begin{tabular}{|c|c|c|}
\hline Beaker glass (mg) & Beaker glass + Sampel (mg) & Sampel (mg) \\
\hline 44638,2 & 46136,2 & 1498,0 \\
44957,0 & 46455,2 & 1498,2 \\
44919,4 & 46425,4 & 1506,0 \\
\hline
\end{tabular}

Tabel 8 Penimbangan Botol Timbang I (Secara Tidak Langsung )

\begin{tabular}{|c|c|c|}
\hline $\mathrm{Ke}$ & Botol timbang I (mg) & Keterangan : \\
\hline $\begin{array}{l}1 \\
2 \\
3\end{array}$ & $\begin{array}{l}21027,6 \\
21023,6 \\
21023,6\end{array}$ & 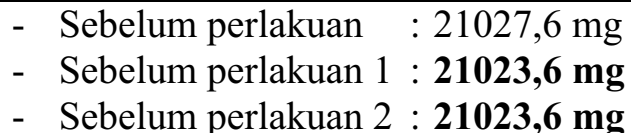 \\
\hline
\end{tabular}

Tabel 9 Penimbangan Botol Timbang II (Secara Tidak Langsung )

\begin{tabular}{|c|c|c|}
\hline $\mathrm{Ke}$ & Botol timbang II (mg) & Keterangan: \\
\hline 1 & 21468,8 & - Sebelum perlakuan \\
\hline 2 & 21316,8 & - Sebelum perlakuan $1: 21316,8 \mathrm{mg}$ \\
\hline 3 & 21281,4 & - Sebelum perlakuan $2: \mathbf{2 1 2 8 1 , 4} \mathbf{~} \mathbf{g g}$ \\
\hline 4 & 21281,4 & - Sebelum perlakuan $3: \mathbf{2 1 2 8 1 , 4} \mathbf{~} \mathbf{~ g}$ \\
\hline
\end{tabular}

Tabel 10 Penimbangan Botol Timbang III (Secara Tidak Langsung )

\begin{tabular}{|c|c|l|}
\hline $\mathrm{Ke}$ & Botol timbang III (mg) & Keterangan : \\
\hline 1 & 21372,2 & - Sebelum perlakuan $: 21372,2 \mathrm{mg}$ \\
2 & 21371,6 & - Sebelum perlakuan 1 : 21371,6 mg \\
3 & 21371,6 & - Sebelum perlakuan 2 : 21371,6 $\mathbf{~ m g}$ \\
\hline
\end{tabular}

Tabel 11 Penimbangan Botol Timbang I + Kertas Saring + Endapan (Secara Tidak Langsung )

\begin{tabular}{|c|c|c|c|}
\hline $\mathrm{Ke}$ & Botol timbang I (mg) & Keterangan: & \\
\hline 1 & 23172,2 & - Sebelum perlakuan & $23172,2 \mathrm{mg}$ \\
\hline 2 & 23026,8 & - Setelah perlakuan 1 & $23026,8 \mathrm{mg}$ \\
\hline 3 & 22952,0 & - Setelah perlakuan 2 & $22952,0 \mathrm{mg}$ \\
\hline 4 & 22949,8 & - Setelah perlakuan 3 & $22949,8 \mathrm{mg}$ \\
\hline 5 & 22949,6 & - Setelah perlakuan 4 & $22949,6 \mathrm{mg}$ \\
\hline 6 & 22949,6 & - Setelah perlakuan 5 & $22949,6 \mathrm{mg}$ \\
\hline
\end{tabular}

Tabel 12 Penimbangan Botol Timbang II + Kertas Saring + Endapan (Secara Tidak Langsung )

\begin{tabular}{|c|c|c|c|}
\hline $\mathrm{Ke}$ & Botol timbang II (mg) & Keterangan : & \\
\hline 1 & 23652,6 & - Sebelum perlakuan & $23652,6 \mathrm{mg}$ \\
\hline 2 & 23527,2 & - Setelah perlakuan 1 & : 23527,2 $\mathrm{mg}$ \\
\hline 3 & 23421,8 & - Setelah perlakuan 2 & $: 23421,8 \mathrm{mg}$ \\
\hline 4 & 23358,0 & - Setelah perlakuan 3 & $: 23358,0 \mathrm{mg}$ \\
\hline 5 & 23258,4 & - Setelah perlakuan 4 & $: 23258,4 \mathrm{mg}$ \\
\hline 6 & 23183,6 & - Setelah perlakuan 5 & $23183,6 \mathrm{mg}$ \\
\hline 7 & 23183,6 & - Setelah perlakuan 6 & : 23183,6 mg \\
\hline
\end{tabular}

Tabel 13 Penimbangan Botol Timbang III + Kertas Saring + Endapan (Secara Tidak Langsung )

\begin{tabular}{|c|c|c|c|}
\hline $\mathrm{Ke}$ & Botol timbang III (mg) & Keterangan: & \\
\hline 1 & 23630,0 & - Sebelum perlakuan & $23630,0 \mathrm{mg}$ \\
\hline 2 & 23520,0 & - Setelah perlakuan 1 & : $23520,0 \mathrm{mg}$ \\
\hline 3 & 23422,8 & - Setelah perlakuan 2 & : $23422,8 \mathrm{mg}$ \\
\hline 4 & 23352,2 & - Setelah perlakuan 3 & : 23352,2 mg \\
\hline 5 & 23291,6 & - Setelah perlakuan 4 & : 23291,6 mg \\
\hline 6 & 23291,4 & - Setelah perlakuan 5 & : 23291,4 mg \\
\hline 7 & 23291,4 & - $\quad$ Setelah perlakuan 6 & : 23291,4 mg \\
\hline
\end{tabular}




\section{Pembahasan}

Perhitungan hasil percobaan untuk cara langsung

A. Berat botol timbang (setelah konstan)

1. Botol timbang I : $19648,4 \mathrm{mg}$

2. Botol timbang II : $21345,2 \mathrm{mg}$

3. Botol timbang III :21004,2 mg

B. Berat botol timbang + sampel mula-mula

1. Botol timbang + sampel I : $21415,4 \mathrm{mg}$

2. Botol timbang + sampel II $: 22779,4 \mathrm{mg}$

3. Botol timbang + sampel III : $22437,8 \mathrm{mg}$

C. Berat botol timbang + sampel akhir (setelah perlakuan)

1. Botol timbang + sampel I $: 21147,2 \mathrm{mg}$

2. Botol timbang + sampel II : $22561,6 \mathrm{mg}$

3. Botol timbang + sampel III : $22220,6 \mathrm{mg}$

D. Berat sampel mula-mula $(B-A)$

1. Berat sampel I : 1767,0 mg $=1,7670 \mathrm{~g}$

2. Berat sampel II : 1434,2 mg $=1,4342 \mathrm{~g}$

3. Berat sampel III : $1433,6 \mathrm{mg}$ $=1,4336 \mathrm{~g}$

E. Berat sampel akhir $(\mathrm{C}-\mathrm{A})$

1. Berat sampel I : $1498,8 \mathrm{mg}$ $=1,4988 \mathrm{~g}$

2. Berat sampel II $=1,2164 \mathrm{~g}$

3. Berat sampel III $=1,2164 \mathrm{~g}$

\section{Untuk sampel I}

Dalam 1,7670 g sampel terdapat 1,4988 $\mathrm{g} \mathrm{BaCl}_{2}$ dengan air kristal sebanyak :

$1,7670 \mathrm{~g}-1,4988 \mathrm{~g}=0,2682 \mathrm{~g}$

$\mathrm{mol} \mathrm{BaCl}_{2}=\frac{1,4988}{208,236}=0,0072 \mathrm{~mol}$

$\mathrm{mol} \mathrm{H}_{2} \mathrm{O}=\frac{0,2682}{18,0153}=0,0149 \mathrm{~mol}$

Dengan perhitungan tersebut dapat diketahui bahwa setiap $0,0072 \mathrm{~mol} \mathrm{BaCl}_{2}$ mengikat $0,0149 \mathrm{~mol} \mathrm{H}_{2} \mathrm{O}$.

Dengan demikian, setiap $1 \mathrm{~mol} \mathrm{BaCl}_{2}$ mengikat 2,0694 $\mathrm{mol} \mathrm{H}_{2} \mathrm{O}$
Analog perhitungan untuk sampel I, pada sampel II didapat bahwa setiap 1 mol $\mathrm{BaCl}_{2}$ mengikat 2,0862 mol $\mathrm{H}_{2} \mathrm{O}$, sedangkan pada sampel III didapatkan bahwa setiap $1 \mathrm{~mol} \mathrm{BaCl}_{2}$ mengikat 2, $0862 \mathrm{~mol} \mathrm{H}_{2} \mathrm{O}$

Perhitungan hasil percobaan untuk cara tidak langsung

A. Penimbangan kertas saring

1. Kertas saring I $504,8 \mathrm{mg}$

2. Kertas saring II $478,4 \mathrm{mg}$

3. Kertas saring III

B. Berat sampel

1. Berat sampel I $1498,0 \mathrm{mg} \quad=1,4980 \mathrm{~g}$

2. Berat sampel II $1498,2 \mathrm{mg} \quad=1,4982 \mathrm{~g}$

3. Berat sampel III $1506,0 \mathrm{mg} \quad=1,5060 \mathrm{~g}$

C. Berat botol timbang (setelah konstan)

1. Botol timbang $\mathrm{I}$ 21023,6 mg

2. Botol timbang I 21281,4 mg

3. Botol timbang I 21371,6 mg

D. Berat botol timbang + kertas saring + endapan (setelah konstan)

1. Botol + kertas saring + endapan I : 22949,6 mg

2. Botol + kertas saring + endapan II : 23183,6 mg

3. Botol + kertas saring + endapan III : $23291,4 \mathrm{mg}$

E. Berat endapan $\mathrm{BaSO}_{4}[\mathrm{D}-(\mathrm{C}+\mathrm{A})]$

1. Endapan I $1421,2 \mathrm{mg} \quad=1,4212 \mathrm{~g}$

2. Endapan II $1423,8 \mathrm{mg} \quad=1,4238 \mathrm{~g}$

3. Endapan III $1423,8 \mathrm{mg}=1,4236 \mathrm{~g}$ 


\section{Untuk Endapan I}

$\mathrm{molBaSO}_{4}=\frac{1,4212}{233,4016}=0,0061 \mathrm{~mol}$

$$
\begin{aligned}
& \text { Reaksi : } \mathrm{BaCl}_{2}+\mathrm{Na}_{2} \mathrm{SO}_{4} \rightarrow \mathrm{BaSO}_{4} \downarrow+2 \mathrm{NaCl} \\
& 0,0061 \quad 0,0061 \quad 0,0061 \quad 0,0122
\end{aligned}
$$

$$
\begin{aligned}
& \mathrm{mol} \mathrm{BaCl}_{2}=0,0061 \mathrm{~mol} \\
& \text { gram } \mathrm{BaCl}_{2}=0,0061 \times 208,236 \\
& =1,2702 \mathrm{~g}
\end{aligned}
$$

Dalam 1,4980 g sampel terdapat 1,2702 $\mathrm{g} \mathrm{BaC}_{2}$ dengan air kristal sebanyak :

$1,4980 \mathrm{~g}-1,2702 \mathrm{~g}=0,2278 \mathrm{~g}$

$\mathrm{mol} \mathrm{H}_{2} \mathrm{O}=\frac{0,2278}{18,0153}=0,0126$

Dengan perhitungan tersebut dapat diketahui bahwa setiap $0,0061 \mathrm{~mol} \mathrm{BaCl}_{2}$ mengikat $0,0126 \mathrm{~mol} \mathrm{H}_{2} \mathrm{O}$. Dengan demikian, setiap $1 \mathrm{~mol}$ $\mathrm{BaCl}_{2}$ mengikat 2,0656 mol $\mathrm{H}_{2} \mathrm{O}$.

Analog perhitungan untuk endapan I, pada endapan II didapatkan bahwa setiap $1 \mathrm{~mol}$

$\mathrm{BaCl}_{2}$ mengikat 2,0820 mol $\mathrm{H}_{2} \mathrm{O}$, sedangkan endapan III didapatkan bahwa setiap $1 \mathrm{~mol}$ $\mathrm{BaCl}_{2}$ mengikat 2, $1475 \mathrm{~mol} \mathrm{H}_{2} \mathrm{O}$.

Berdasarkan hasil percobaan yang menunjukkan beragamnya jumlah mol $\mathrm{H}_{2} \mathrm{O}$ yang terikat pada 1 mol $\mathrm{BaCl}_{2}$ pada gravimetri langsung maupun gravimetri tidak langsung, mengindikasikan bahwa masih perlu dicari "kondisi-kondisi" yang diperlukan untuk mendapatkan hasil yang terbaik, karena pada dasarnya untuk kedua metoda tersebut belum ada prosedur yang baku. Walaupun dengan uji statistik menunjukkan bahwa cara gravimetri tidak langsung tidak berbeda dengan cara gravimetri langsung.

\section{KESIMPULAN}

Dari hasil penetapan jumlah air kristal pada $\mathrm{BaCl}_{2}$ secara gravimetri, didapatkan :

1. Untuk gravimetri langsung bahwa setiap 1 mol $\mathrm{BaCl}_{2}$ mengikat 2,0862 $\mathrm{mol} \mathrm{H}_{2} \mathrm{O}$.

2. Untuk gravimetri tidak langsung bahwa setiap $1 \mathrm{~mol} \mathrm{BaCl}_{2}$ mengikat 2,0738 $\mathrm{mol} \mathrm{H}_{2} \mathrm{O}$.

\section{DAFTAR PUSTAKA}

Alexeyef V (1967), A Textbook of Quantitative Inorganic Analysis, Third edition, 56-58, MIR Publishers, Moscow.

Blaschke E dan Roth H.J (1988), Analisis Farmasi, 113 - 143, Gadjah Mada University Press, Yogyakarta

Day R. A \& Underwood A.L (1983), Analisa Kimia Kuantitatif, Edisi ke IV, 73 - 95, 577 - 587, Erlangga, Jakarta.

Departemen Kesehatan RI (1979), Farmakope Indonesia, Edisi ke III, Jakarta.

Fatah A.M dan Mursydi (1978), Pengantar Kimia Farmasi, Analisa Volumetri dan Gravimetri, 159 - 172, Fakultas Farmasi, UGM, Yogyakarta.

Haryadi W (1986), Ilmu Kimia Analitik Dasar, 89 - 110, Gramedia Jakarta.

Pierce W.C, Haenisch E.L, Sawyer DT, (1958) Quantitative Analysis, Fourth Edition, 337 - 352, John Wiley and Son, Inc, New York.

Stecher RE (1968), The Merck Index, Eighth Edition, 120, Merck \& Co, Inc, Rahway, N.J, USA.

Vogel A.1 (1972), A Textbook of Quantitative Inorganic Analysis, Third Edition, 211-227, Longman, London. 